\title{
Mulheres na dendeicultura paraense: possibilidade de autonomia
}

DOI: $10.36920 /$ esa-v28n3-10

\section{Diocélia Nascimento $^{1}$ | (iD) Dalva Maria da Mota ${ }^{2}$}

Resumo: A relação entre iniciativa econômica e conquista de autonomia pelas mulheres é consensual na literatura. Considerando essa constatação, o objetivo do artigo é analisar a relação entre iniciativa econômica e conquista de autonomia por mulheres titulares de contratos de integração para a produção de dendê no Nordeste Paraense, maior região produtora de dendê do Brasil. A pesquisa foi realizada como um estudo de caso com 30 mulheres (100\% das mulheres titulares de contratos no município de São Domingos do Capim/PA) e por meio de observações e entrevistas. As principais conclusões mostram que: I) a participação de mulheres em iniciativas econômicas, por si só, não garantiu a autonomia, mas a incentiva; II) a autonomia tem relação direta entre a decisão própria para assinar o contrato e a gestão em diferentes etapas de produção no cultivo do dendê; III) a construção da autonomia ampara-se na obtenção de recursos financeiros, independência para tomar decisões, participação nas esferas públicas, acesso a diferentes informações, diálogo com técnicos da empresa dendeicultora e com representantes de instituições públicas; e IV) ter um contrato de produção representa para as mulheres uma estratégia de conquista de autonomia, embora essa autonomia nem sempre seja exercida da mesma forma.

Palavras-chave: agricultoras; integração; Nordeste Paraense.

Abstract: (Women in oil palm cultivation in Pará: possibility of autonomy). The relationship between economic initiative and women's autonomy is consensual in the literature. Considering this finding, the objective of the article is to analyze the relationship between economic initiative and the achievement of autonomy by women holding integration contracts for oil palm production in Northeast Para, Brazil's largest oil palm region. The research was carried out as a case study with 30 women (100\% of women holding contracts in the municipality of São Domingos do Capim / PA) and through observations and interviews. The main conclusions show that: I) the participation of women in economic initiatives, by itself, did not guarantee autonomy, but encourages it; II) autonomy has a direct relationship between the decision to sign the contract and management at different stages of production in oil palm cultivation; III) the construction of autonomy is supported by obtaining financial resources, independence to make decisions, participation in public spheres, access to different information, dialogue with technicians from the oil palm company and with representatives of public institutions; and IV) having a production contract represents a strategy for women to achieve autonomy, although this autonomy is not always exercised in the same way.

Keywords: women farmers; integration; Northeastern Pará.

\footnotetext{
1 Doutoranda em Agriculturas Familiares e Desenvolvimento Sustentável pela Universidade Federal do Pará (UFPA). E-mail: diocelianascimento@yahoo.com.br.

${ }^{2}$ Pesquisadora da Empresa Brasileira de Pesquisa Agropecuária da Amazônia Oriental (Embrapa Amazônia Oriental). Professora permanente do Programa de Pós-graduação em Agriculturas Familiares da Universidade Federal do Pará (UFPA). Pós-doutorado na University of London, Inglaterra. Doutorado em Sociologia pela Universidade Federal de Pernambuco (UFPE). E-mail: dalva.mota@embrapa.br.
} 


\section{Introdução}

$\mathrm{O}$ artigo trata da relação entre iniciativa econômica e autonomia de mulheres na produção de dendê no estado do Pará, na Amazônia Oriental. Trata, portanto, de um tema cujo debate tem múltiplos aportes na literatura, muito embora Gilbert de Terssac (2012) ressinta-se da menor importância do conceito na sociologia em comparação com a psicologia e a biologia. $\mathrm{O}$ autor ressalta que, mesmo quando tratado na sociologia, o conceito suscita muitas controvérsias. Para uns, é impróprio para conceber o social, dada a impossibilidade de autonomia do sujeito; para outros, a autonomia é uma característica essencial da ação humana nas relações que se dão no nível microssociológico - concepção à qual se filia o autor.

Segundo Terssac (2012, p. 47), a "autonomia é a capacidade de se conduzir segundo as suas próprias regras construídas à margem ou contra o sistema de regras oficiais”. A autonomia é, portanto, a capacidade estratégica de afirmação de suas escolhas. Para o autor, o conceito ocupa um lugar central nos estudos de Crozier porque envolve relações de poder, além de estar vinculado à autonomia do ator racional e estratégico e à recusa de qualquer determinismo, a priori, porque os atores não estão diluídos em uma vida social, mas enraizados em jogos de relação de poder que se constroem nas zonas de incerteza nas quais cada um tenta obter do outro aquilo que atende aos seus interesses (CROZIER, 1963 apud TERSSAC, 2012).

No meio rural, as relações de poder estão associadas imaginariamente à separação entre a esfera da "produção", ligada à produção de mercadorias (valor de troca), e a da "reprodução", atribuída às mulheres no interior da casa (valor de uso) como aponta Reigada (2014), o que repercute nas investigações sobre o exercício da autonomia. Em decorrência disso, ainda prevalecem as análises associadas às relações econômicas, provavelmente porque há consenso entre os estudiosos quanto à dificuldade de conquistar a autonomia sem qualquer forma de suporte financeiro.

Em estudos de caso no Brasil, Schefler (2013) analisa a autonomia como uma consequência do processo de empoderamento incentivado por políticas públicas para a agricultura familiar, ainda que afirme ser a autonomia constituída para além de um aumento da importância econômica da produção. Nessa mesma perspectiva, Martínez Dajui (2006) e Zorzi (2008) inter-relacionam a autonomia com determinados aspectos econômicos, nos quais atividades produtivas tendem a culminar com a geração de renda por meio do acesso a créditos agrícolas ou ainda com a ampliação das atividades produtivas valorizadas pelo mercado consumidor, antes voltadas somente para o autoconsumo (WEDIG, 2009). Adicionalmente, outros atributos têm sido considerados na literatura como sinônimos de autonomia, como os relacionados ao poder de decisão 
quanto à organização do trabalho e ao uso dos recursos dele provenientes (FERNANDES; MOTA, 2014; VALE, 2015) e à autonomia física relativa às decisões sobre o próprio corpo, em relação à maternidade (SOARES, 2011). Os diferentes olhares têm em comum o reposicionamento econômico da mulher, que assume o papel de trabalhadora com reconhecimento social.

Neste artigo, abraçamos o desafio analítico de aliar a iniciativa econômica à capacidade de decisão para a conquista de autonomia por parte das mulheres. Para tal, focamos na autodeterminação das mulheres para organizar e desenvolver o trabalho, mas também na sua participação em outras esferas da vida social e política, definindo os próprios objetivos e agindo em consequência deles (FERNANDES; MOTA, 2014). Tomamos como referência empírica mulheres titulares de contratos de integração para a produção de dendê no município de São Domingos do Capim, Nordeste do Pará. O estado do Pará lidera a produção de dendê no Brasil sob forte apelo socioambiental e com o apoio de políticas públicas efetivadas a partir de 2003.

Partimos do pressuposto de que a conquista da autonomia depende da qualidade do engajamento e das predisposições individuais e coletivas, e buscamos responder a seguinte questão: como a participação de mulheres em uma iniciativa econômica formal - evidenciada pela titularidade de um contrato de produção - influi no exercício da sua autonomia?

\section{Metodologia}

O nosso campo de pesquisa foi o município de São Domingos do Capim. A economia do município gira em torno da produção de mandioca (Manihot esculentum Crantz), fonte de alimento e objeto de comercialização para as populações amazônicas (RIBEIRO et al., 1999; SOUZA, 2006). O principal produto é a farinha de mandioca, que se destina tanto ao consumo como à venda. O extrativismo de açaí (Euterpe oleracea Mart.) e a produção de dendê passaram a constar mais recentemente na pauta das atividades em razão do apelo de mercados globais.

A instalação da dendeicultura no município remonta ao ano de 2010 (GOMES; MAGALHÃES, 2016) e teve repercussão considerável após o lançamento do Programa de Produção Sustentável de Óleo de Palma (PSOP) pelo então presidente Luiz Inácio Lula da Silva, no município de Tomé-Açu (MONTEIRO, 2013; SAMPAIO, 2014; SOUSA, 2015; GOMES; MAGALHÃES, 2016). 
Figura 1 - Localidades onde residem mulheres com contrato de integração na dendeicultura, São Domingos do Capim/PA

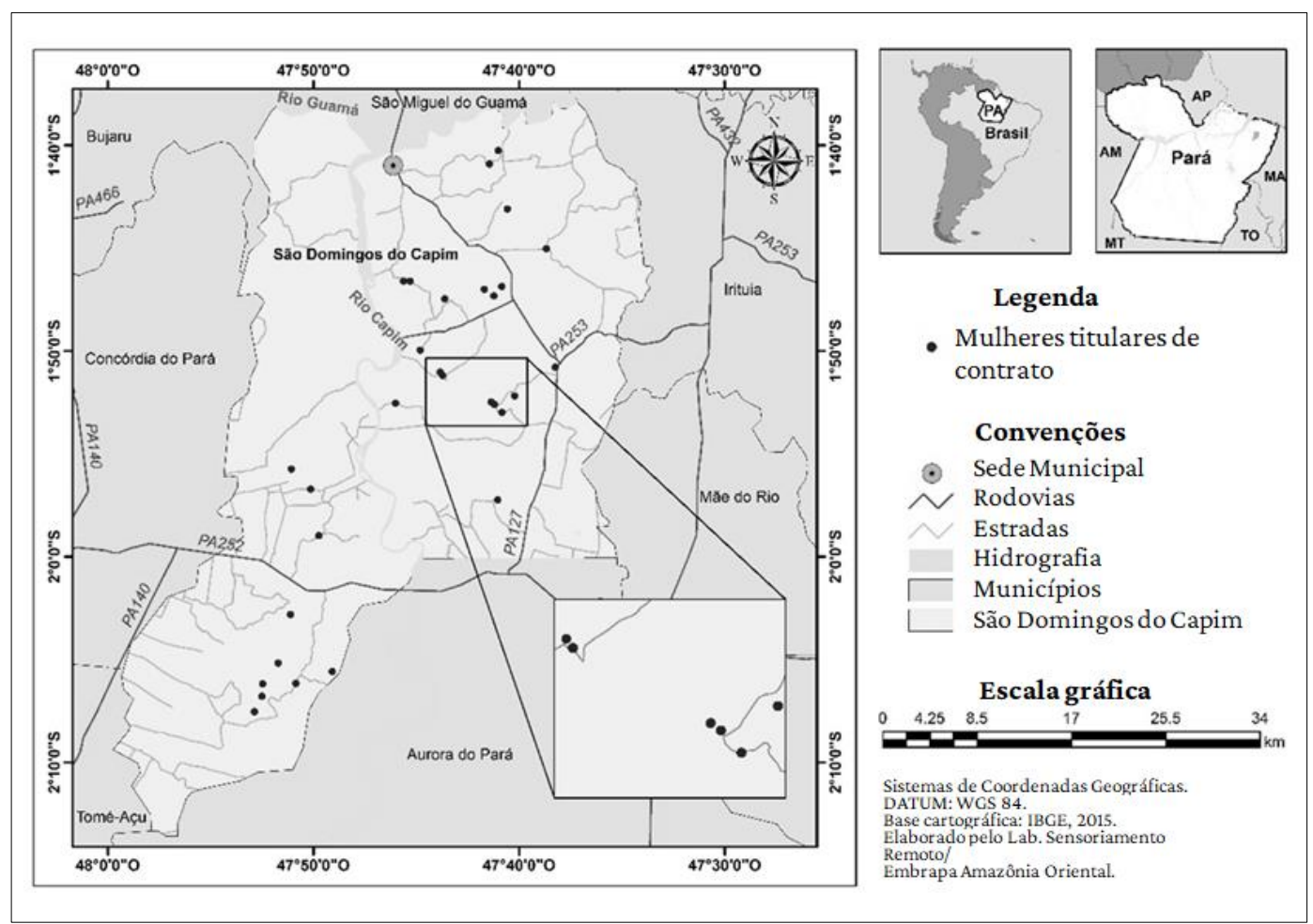

Fonte: Pesquisa de campo, 2017.

Nos anos seguintes, a prefeitura de São Domingos do Capim assinou um acordo de cooperação com a Empresa de Assistência Técnica e Extensão Rural (Emater) para estimular a efetivação dos procedimentos necessários à execução da assistência técnica destinada aos agricultores familiares interessados na produção de dendê, no sistema de integração com as agroindústrias (GOMES; MAGALHÃES, 2016).

Cabe ressaltar que nessas circunstâncias a empresa Archer Daniels Midland (ADM) ${ }^{3}$ pretendia construir uma usina de processamento de dendê na comunidade de Perseverança, em São Domingos do Capim, em parceria com diferentes atores sociais e representantes do estado (NAHUM; BASTOS, 2014; NAHUM; MURRAY, 2014). Ainda segundo Nahum e Bastos (2014), a promessa declarada pela ADM contava com a produção de 600 famílias com contratos de produção (cada agricultor poderia plantar até 10 ha em suas terras), o que responderia por 50\% da produção, enquanto a outra

\footnotetext{
${ }^{3}$ A empresa comprometeu-se a construir uma usina de processamento com capacidade de esmagar até 60 toneladas de cachos de frutos frescos (CFF) por hora. Caso fosse efetivado tal empreendimento, a ADM teria o monopólio local de uma área de 24 mil hectares, considerada a reserva legal (NAHUM; BASTOS, 2014).
} 
metade seria produzida em terras próprias da empresa, totalizando 12.000 ha de plantio na região. ${ }^{4}$

Naquele contexto, os agricultores familiares de São Domingos do Capim assinaram contratos de produção com as agroindústrias atuantes na região. No total, 226 agricultores familiares assinaram o contrato, sendo $87 \%$ assinados pelos homens e $13 \%$, pelas mulheres até o ano de 2015 (BANCO DA AMAZÔNIA, 2015). Hoje 30 mulheres têm contratos de integração em seus nomes em São Domingos do Capim e residem em 17 diferentes localidades do município (Figura 1). Os seus contratos são com as empresas ADM e Biopalma da Amazônia S.A. (Biopalma) a partir de 2010.

A pesquisa deu-se por meio da combinação das abordagens quantitativa e qualitativa no período de 2016 a 2017. Estudos de caso foram realizados com 30 mulheres (13\% do total dos contratos no município) que se autodesignam como agricultoras ou lavradoras e que foram, neste artigo, identificadas por nomes fictícios, com denominações de flores, para garantir o anonimato. Como procedimentos, realizamos entrevistas semiestruturadas com uso de formulário combinando questões fechadas e abertas. Além disso, entrevistas abertas ocorreram com técnicos, lideranças, pesquisadores e sindicalistas. Foram realizadas observações in loco, anotações em diário de campo, gravações e fotografias. Os dados obtidos foram tratados meticulosamente após cada período em campo à luz do diálogo com a literatura sobre autonomia, trabalho e políticas públicas.

\section{Perfil das mulheres titulares de contratos}

As mulheres residem em 17 localidades, ${ }^{5} 73 \%$ vivem no próprio estabelecimento, localmente denominado "lote" por ter sido demarcado em uma ação de legalização da posse da terra. Desse total, 21 mulheres (70\%) têm a titularidade da terra de acordo com a Instrução Normativa no 38/2007 do Instituto Nacional da Colonização e Reforma Agrária (Incra), que tornou obrigatória a inclusão delas como beneficiárias da reforma agrária no Brasil. As demais - 9 mulheres (30\%) - tiveram acesso à terra por herança ou compra. Há diferença entre elas no que concerne às condições de habitação. As do primeiro grupo moram em casas de alvenaria construídas como parte das ações da reforma agrária; as demais vivem em casas de taipa ou madeira. Todas as residências têm quintais onde são criados pequenos animais sob a responsabilidade das mulheres, quer sejam para o trabalho, quer sejam para alimentação, condição também observada

\footnotetext{
${ }^{4}$ Em janeiro de 2020, a ADM anunciou o encerramento de suas atividades na região. A venda de seus aditivos foi para o Grupo Marborges que também atua em toda a cadeia produtiva do dendê (REUTERS, 2020).

${ }^{5}$ Nova Luz, Santa Maria Quatro, São Sebastião, Filadélfia, Nova Caminhada, Rancho Fundo, Baixo Palheta, Nova Betel, Nova Esperança do Bentil, São José do Itabocal, Novo Bom Jardim (km 17), Fé em Deus, São Benedito do Jaboticacá, Catita, Manteiga, Monte Sinai e Bom Jesus. Os nomes geralmente são associados a passagens bíblicas ou são nomes de antigas fazendas das quais a comunidade surgiu; há até nomes de santos, os mais comuns.
} 
em outros contextos quanto à preocupação das mulheres com a produção e reprodução (FERRANTE et al., 2013).

Conforme constatamos, $70 \%$ delas são oficialmente casadas, 13\% são solteiras, $13 \%$ são viúvas e $4 \%$ divorciadas. É interessante observar como a posse da terra e o casamento são fatores quase inseparáveis para que as mulheres tenham acesso a terra, embora notemos que, para estas mulheres, tal acesso tenha ocorrido por diferentes caminhos. O mais frequente foi um dos cônjuges, ao se casar, receber uma parcela de terra, construir uma casa no lote dos pais e continuar trabalhando com eles até conseguir comprar sua própria terra. Conforme apontou Brumer (2004), a "parceria familiar" (os membros de uma mesma família trabalham em conjunto e, posteriormente, dividem os recursos obtidos com os filhos casados) consiste em uma estratégia que envolve os jovens após o casamento. Ou seja, a doação de uma área para produzir e usufruir dos benefícios do seu trabalho, mas de forma independente dos pais, que os auxiliam nos anos iniciais da formação de um novo núcleo familiar.

As mulheres que assinaram contrato para a produção de dendê estão na faixa etária de 23 a 81 anos. Dentre elas, 21 mulheres (71\%) têm entre 30 e 49 anos, faixa etária apontada na literatura como a mais frequente para mulheres que participam de programas de microfinanciamento de atividades agropecuárias, agroindustriais e artesanais (MARTÍNEZ DAJUI, 2006). No estudo de Melo e Di Sabbato (2008), as mulheres de 30 a 49 anos representavam $56 \%$ das responsáveis pelos lotes oriundos da reforma agrária. Nessa fase da vida, há um número elevado de mulheres com filhos adolescentes ou já adultos que não dependem de cuidados exclusivos, o que permite mais dedicação ao trabalho fora do domicílio.

Em se tratando do número de filhos, $40 \%$ das entrevistadas têm entre sete e 12 filhos; $26 \%$, entre quatro e seis filhos; $24 \%$ entre um e três filhos; e $10 \%$ não tiveram filhos. As entrevistadas mais jovens que possuem filhos ainda pequenos associam a idade dos filhos à menor ou maior disponibilidade para o trabalho fora de casa. Essa condição não é restrita ao meio rural, pois segundo o que relataram Bruschini (2007) e Soares (2011) a participação das mulheres no mercado de trabalho no Brasil em atividades produtivas é menor quanto menor seja a idade dos filhos. Essa realidade também foi pontuada por Martinez (2010) em duas comunidades rurais do Uruguai, onde o tempo dedicado aos cuidados com os filhos pequenos impedem as mulheres de participar dos encontros comunitários.

As mulheres com maior idade e maior número de filhos (33\%), principalmente as viúvas, sonham em trazer os filhos, que haviam migrado para trabalhar em outros 
locais, de volta para a terra, pois acreditam que o dendê é uma atividade que lhes possibilitará trabalho em longo prazo, e também os mantendo próximos a elas.

O nível predominante de escolaridade das entrevistadas é o Ensino Fundamental incompleto - 20 mulheres (67\%); e as demais (23\%) não têm escolaridade formal. ${ }^{6}$ Nas suas falas, elas recordam a precariedade de acesso às escolas pela distância, pela falta de transporte e pela condição financeira dos pais, fatores que marcaram a vida das mulheres com mais de 60 anos. Apesar de a escolaridade formal ser baixa neste estudo, as mulheres mais jovens possuem mais anos de escolaridade, devendo esse fato ser considerado como uma possível fuga da situação vivenciada por suas mães e/ou exclusão de posse da terra futuramente (BRUMER, 2004), ou pela busca de alternativas para realização pessoal e empregos não agrícolas (ZORZI, 2008).

\section{A assinatura do contrato para a produção de dendê: decisão de quem?}

Estudos sobre a agricultura por contrato ou integrada demonstram que o modelo data do início do século XX, mas que no Brasil foi intensificado nos anos 1970 com a produção de fumo, frutas, madeiras e animais - suínos e aves - (PAULILO, 1990; AQUINO, 2013; MARIN; REDIN, COSTA, 2014), principalmente no Sudeste e Sul do Brasil.

Recentemente o sistema de agricultura por contrato foi viabilizado no Pará para a produção de dendê. A iniciativa é parte do Programa Nacional de Produção e Uso do Biodiesel (PNPB). Lançado em 2004, o PNPB objetiva estimular a produção de agrocombustíveis no país e traz, entre os seus componentes, o Selo Combustível Social (SCS) que incentiva a integração ${ }^{7}$ por meio de contratos entre agricultores e as agroindústrias. Compete aos agricultores produzir e fornecer matéria-prima para as empresas. A estas, compete comprar a produção dos agricultores, além de proporcionar assistência técnica e capacitação condizentes com a garantia de segurança alimentar.

No Pará, segundo estudo recente (BRANDÃO; SCHONEVELD; PACHECO, 2018), o dendê alcança uma área de 207.000 ha com aproximadamente $80 \%$ no sistema de plantation e 20\% em médios (181 produtores) e pequenos estabelecimentos (1.508 agricultoras familiares com contratos na condição de integração). A Associação Brasileira de Produtores de Óleo de Palma (2015) estima que os cultivos juntamente com as plantas de processamento do dendê gerem aproximadamente 20 mil empregos diretos.

Em São Domingos do Capim, a possibilidade de ter um contrato suscitou debates e controvérsias que persistiam até a realização da nossa pesquisa. Como tal, foram

\footnotetext{
${ }^{6}$ Duas mulheres possuem o Ensino Médio completo (7\%) e apenas uma tem o Ensino Médio incompleto (3\%).

${ }^{7}$ SCS - Selo a ser obtido por empresas (mediante a integração de agricultores familiares) para ter incentivos financeiros do Banco Nacional de Desenvolvimento Econômico e Social (BNDES) e demais instituições de crédito, direito à desobrigação de impostos e reserva na ordem de $80 \%$ do mercado de biodiesel. A condição era cumprir todas as obrigações previstas no PNPB com os agricultores integrados.
} 
desencadeados debates intra e interfamiliares que culminaram com a aderência ou não. Dentre as principais justificativas para aderir está a crise enfrentada pela produção de mandioca e, para rejeitar, o medo da perda de autonomia no "lote" e dívida contraída para a obtenção do crédito rural.

No tocante às razões para a assinatura do contrato, a grande maioria das mulheres nos explicou os motivos ( 26 mulheres, $86 \%$ das entrevistadas). Não obstante, de uma minoria não conseguimos a explicação quanto ao tema (quatro mulheres ou 14\%). No primeiro caso, as mulheres diferenciam-se em grupos porque algumas resolveram sozinhas (decisão própria). Outras, em conjunto com seus cônjuges (decisão familiar), e outras atenderam ao pedido de um dos homens da família (decisão de um homem). As evidências nos informam que diferentes arranjos podem ocorrer segundo a disponibilidade dos recursos, o sistema de posições dos diferentes membros da família e as relações de reciprocidade, dentre outras possíveis explicações, como veremos nos seus depoimentos.

As mulheres que decidiram por conta própria (10 mulheres, 33\%) evidenciam que têm motivos diferenciados para a assinatura dos contratos:

Pensei em melhorar porque eu queria uma renda melhor, conforme o informado pela empresa. E mesmo assim, a roça não dava mais, estava morrendo tudo, e a gente precisa plantar outras coisas. (Margarida, 47 anos, divorciada, agricultora)

[...] em primeiro lugar nossa terra não presta para outra cultura, principalmente para a mandioca. A gente mexe com a mandioca, aí a nossa área não presta para mandioca. Esse projeto foi o único projeto que meu marido gostou, aí fizemos e, desde essa época que nós fizemos, ajudou muito. A gente estava sem a roça, aí ajudou a sair o dinheiro para a gente. (Iris, 36 anos, casada, agricultora)

Em comum, elas alegam a possibilidade de ter uma atividade capaz de gerar renda e de ampliar as iniciativas produtivas da família num contexto com raras oportunidades de emprego e renda no local onde vivem. Importante lembrar que em diferentes contextos, mulheres protagonizam experiências inovadoras, a exemplo da constatação recente de Siliprandi (2017), na produção agroecológica e orgânica.

As mulheres do grupo que decidiram juntamente com a família ter os contratos em seus nomes (10 mulheres, 33\%) explicaram que os outros familiares estavam impedidos, quer por inadimplência, quer por terem outro financiamento. Em um único caso, a família cogitou que seria importante um novo aprendizado para a titular.

Um grupo de seis mulheres (20\%) assinou para atender ao pedido do marido, dos filhos ou dos irmãos. Essas reconhecem que se tratou de um ato meramente formal, um empréstimo do nome, às vezes constrangidas porque não queriam dívidas bancárias. Há 
casos em que só elas assinavam na família, condição que facilitou a burocracia. Diante disso, pode-se afirmar que o fato de a escolaridade entre as mulheres ser maior que entre os homens torna-se um elemento condicionante para que o contrato seja vinculado a elas, resolvendo assim as pendências formais que culminam com a aprovação do financiamento e liberação do crédito agrícola. No Rio Grande do Sul, Brumer (2004) mostrou como o nível de escolaridade para as mulheres se apresenta como novas possibilidades de inserção em atividades não agrícolas, desejo de saída de suas comunidades de origem e almejo por outra forma de viver ligada aos centros urbanos. Para a autora, isso ocorre porque elas são culturalmente excluídas do acesso a terra e possuem baixa inserção em empregos formais no meio rural (BRUMER, 2004). As mulheres que atenderam ao pedido de um homem da família são vistas como potenciais captadoras de recursos, capazes de assumir a responsabilidade de um empréstimo, porém, incapazes de negociar ou administrar os recursos financeiros entre os membros de sua própria família.

Apenas de quatro mulheres (14\%) não conseguimos a explicação ${ }^{8}$ porque o contrato estava nos seus nomes em decorrência de problemas de saúde que as impossibilitaram de manifestar-se sobre o tema. Em todo caso, inferimos que os contratos de produção estão em seus nomes porque elas possuem todos os documentos exigidos (principalmente da propriedade da terra) e um dos membros da família possui uma procuração para representá-las nas agências financiadoras e na empresa.

Dentre as 30 mulheres entrevistadas, somente quatro (14\%) já haviam adquirido pelo menos um financiamento em seu nome. Portanto, para 26 mulheres (87\%), foi o primeiro contato com agentes financiadores e com a burocracia concernente.

Após a análise do conjunto das famílias das entrevistadas, constatamos que elas têm em comum dificuldades para garantir a reprodução do grupo doméstico. Os problemas que enfrentavam para cultivar a mandioca - em decorrência da podridão, da baixa fertilidade do solo e da crise do sistema de corte e queima - associados à carência de assistência técnica e ao reduzido financiamento influíram na decisão de aderir ao cultivo do dendê com crédito, assistência técnica, mercado e "promessa de lucro". Ademais, há muita expectativa quanto à cultura permanente que, na experiência preexistente, traz recordações do extrativismo e de tempos de fartura.

Muito embora as dificuldades cotidianas no "lote" justifiquem a opção pela dendeicultura, as mulheres dividem-se, grosso modo, entre as que quiseram assinar e as que foram convencidas. Entretanto, diante das dificuldades de reprodução social, elas

\footnotetext{
${ }^{8}$ As quatro mulheres que fazem parte desse grupo não foram incluídas nas análises porque não foi possível entrevistá-las.
} 
concordaram, na expectativa de melhoria nas condições de vida da família. Na essência, essa posição não difere daquela identificada por Neves em Santarém no Pará:

[...] o objetivo fundamental do engajamento econômico das mulheres é se constituir como sujeito de ações para colaboração na melhoria das condições habitacionais e do grau de ensino para os filhos, especialmente se, acumulativos, eles puderem redundar em profissionalizações reconhecidas. (2014, p. 33)

Mesmo que concordemos com a semelhança, há mulheres dentre as entrevistadas que questionam a dendeicultura como opção para a agricultura familiar porque não permite alternatividade e não oferece segurança alimentar.

\section{A organização do trabalho na produção de dendê: relação entre querer e fazer}

Estudos demonstram uma diferença importante entre o trabalho de homens e de mulheres na dendeicultura no mundo, quer seja nas áreas de plantation, quer seja nas áreas de produção familiar. Nas primeiras, a razão central para a predominância dos homens é sua maior mobilidade, pois migram e deixam sob o encargo das mulheres os filhos e atividades que porventura possuam nos seus lugares de origem (ARNDT; BENFICA; THURLOW, 2011; LI, 2014; SAMPAIO, 2014). Nas segundas, há privilégio dos homens como interlocutores em uma atividade considerada especializada e pesada para mulheres, não obstante o debate em torno das noções de leve e pesado realizado por Paulilo (1987). Sob tais condições, as mulheres atuam entre as esferas da produção e reprodução para garantir o aprovisionamento dos seus grupos domésticos, contrariando a visão que as associa, predominantemente, a esta última (REIGADA, 2014).

No Pará, estudos mostram que o trabalho na dendeicultura é preponderantemente masculino e que os discursos afirmam que as mulheres apenas "ajudam” (SAMPAIO, 2014; VIEIRA, 2015). Em diálogo com um pesquisador que estuda a temática da dendeicultura no Nordeste paraense, ele relatou que visitou mais de 900 estabelecimentos e entrevistou somente homens porque não viu mulheres trabalhando na dendeicultura. A constatação nos incentiva a questionar se as mulheres não trabalham ou não foram envolvidas na pesquisa. Nesse sentido, concordamos com Neves e Motta-Maués (2013) para quem os papéis desempenhados pelas mulheres rurais devem ser analisados não somente do ponto de vista das situações empíricas, mas, sobretudo, no próprio fazer intelectual nos processos de construção das unidades de análises e observações. Com essa orientação, confirmamos que as mulheres trabalham em diferentes etapas do itinerário técnico, com 50\% delas participando diretamente da produção, conforme detalhamos no Gráfico 1. 
Gráfico 1 - Participação das mulheres por atividade no itinerário técnico por grupo, São Domingos do Capim/PA

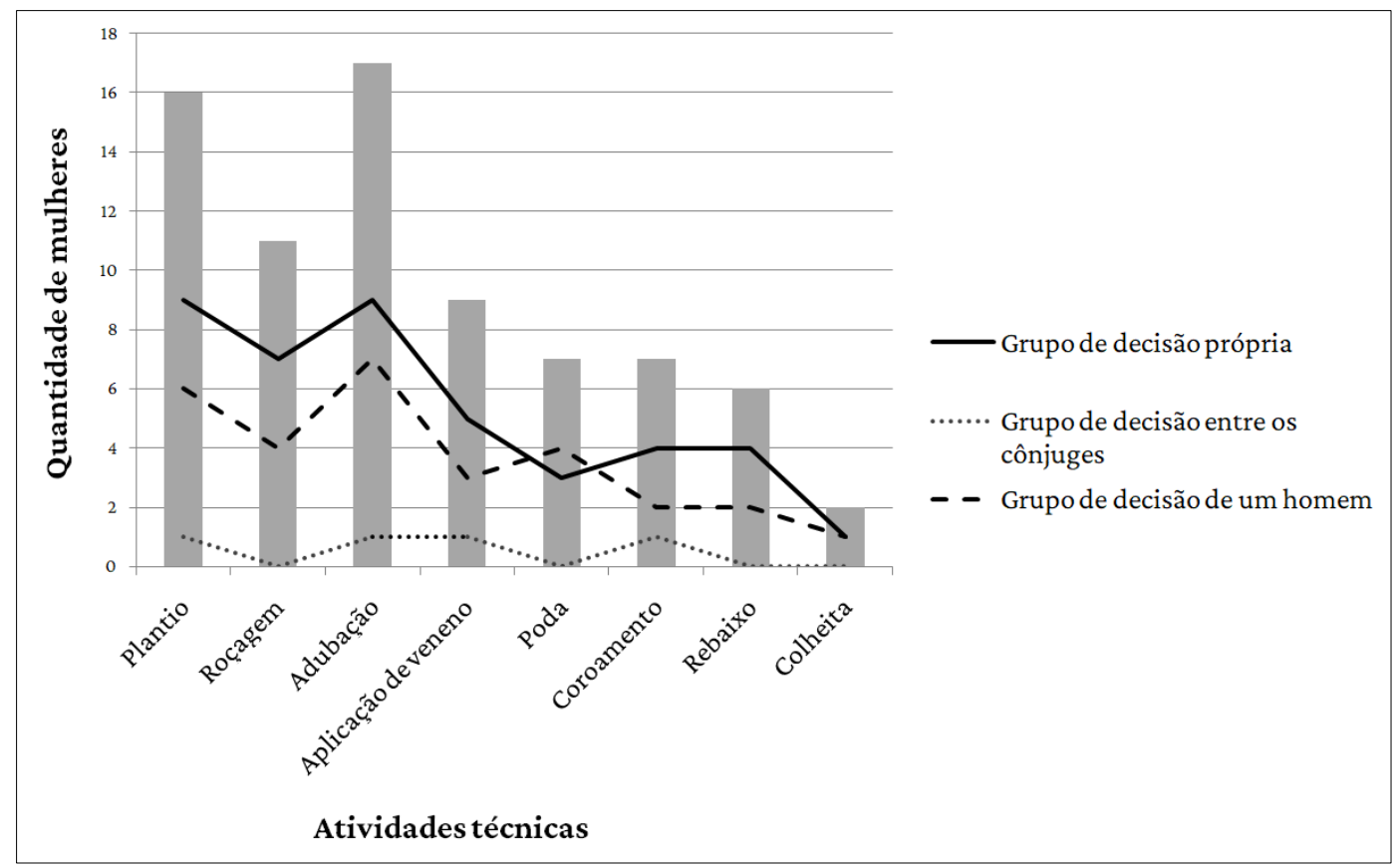

Fonte: Pesquisa de campo, 2016.

Conforme o gráfico, constatamos que o trabalho das mulheres predomina na adubação (17 mulheres ou 56\%) e no plantio (16 mulheres ou 53\%). Os cultivos ainda estão nos anos iniciais, isso explica o fato de apenas duas mulheres (6\%) afirmarem já ter realizado a colheita. No entanto, quando comparado com outros cultivos, o trabalho na dendeicultura é considerado mais penoso para todos. Para as famílias que possuem o contrato de produção a área plantada aumentou, consequentemente, o volume de trabalho também. Já o peso é o argumento central para a visibilidade dada aos homens e para a minimização do trabalho das mulheres. De acordo com Paulilo (1987), a noção de "leve" ou "pesado" depende de quem realiza o trabalho, não da sua penosidade. De fato, não é a natureza do trabalho que determina que ele é de homem ou de mulher, mas o imaginário coletivo, intimamente relacionado à hierarquização que serve de alicerce para a divisão sexual do trabalho entre os membros da família. Assim, concordamos com Hirata e Kergoat que:

A divisão sexual do trabalho é a forma de divisão do trabalho social decorrente das relações sociais entre os sexos; mais do que isso, é um fator prioritário para a sobrevivência da relação social entre os sexos. Essa forma é modulada histórica e socialmente. Tem como características a designação prioritária dos homens à esfera produtiva e das mulheres à 
esfera reprodutiva e, simultaneamente, a apropriação pelos homens das funções com maior valor social adicionado (políticos, religiosos, militares etc.) [...] Essa forma particular da divisão social do trabalho tem dois princípios organizadores: o princípio de separação (existem trabalhos de homens e trabalhos de mulheres) e o princípio hierárquico (um trabalho de homem "vale" mais que um trabalho de mulher). Esses princípios são válidos para todas as sociedades conhecidas, no tempo e no espaço. Podem ser aplicados mediante um processo específico de legitimação, a ideologia naturalista. Esta rebaixa o gênero ao sexo biológico, reduz as práticas sociais a "papéis sociais" sexuados que remetem ao destino natural da espécie. (2007, p. 599)

Os princípios aludidos pelas autoras se expressam na fala de Narciso (57 anos, agricultor), representante da associação de uma das localidades onde realizamos a pesquisa. Quando nos referimos ao trabalho das mulheres na dendeicultura, ele afirmou categoricamente: “até agora elas [as mulheres] não fazem nada!”. Diferentemente, os depoimentos de mulheres integradas relativizam esse discurso. Margarida (47 anos, agricultora), por exemplo, afirma estar envolvida com as atividades agrícolas do dendê. Segundo seu depoimento, mesmo que não esteja no trabalho braçal, gosta de observar:

Olha, eu só não faço botar veneno. Mas tirar, eu aprendi tirar, limpar, eu aprendi limpar, só não posso mais colocar veneno [...] Eu passo mal, me dá alergia, me coço. Mesmo que estiver borrifando perto, eu não posso.

Chama a atenção a afirmação "eu aprendi” porque remonta a uma atividade que não era corriqueira e também se refere a uma das atividades mais citadas no processo de veiculação do discurso sobre os princípios hierárquicos. Ou seja, atividade muito valorizada nas falas porque é predominantemente realizada por homens. Como visto, a participação de Margarida ocorre em praticamente todas as fases do processo produtivo e contrapõe-se à noção de que o trabalho com o dendê é masculino por ser pesado:

[...] tem pessoas que dizem assim, égua, como é que tu consegues trabalhar? Eu vou de bota, vou de chapéu, vou de blusa mangas compridas, às vezes os meninos do dendê chegam até me confundir e dizer: ei, senhor, quando eu viro, pedem desculpa. Desse jeito, chegam me confundir. Aí os meninos riem de mim, porque eu digo assim, amanhã eu vou trabalhar, vou brocar, vou fazer o rodapé do dendê. O que tu pensas para fazer isso? Tu pensas que tu és homem? Quando é a noite, eu sei o que eu vou fazer pela manhã, eu digo assim: amanhã eu vou amanhecer com a força de macho, mas uma força mesmo, de um macho mesmo. Se eu não falar isso, talvez eu não dê conta, se eu falar, eu dou. Eles começam a rir de mim. Assim que eu venço. (Margarida, 47 anos, divorciada)

Por mais que ela tenha consciência de seu trabalho e esteja à frente das atividades agrícolas, Margarida atribui seu desempenho ao próprio mérito, mas acredita que "sua 
força" é de "macho" por dar conta de trabalhos que se convencionou rotular de masculino no rol dos princípios de hierarquização.

\section{Participação de mulheres na dendeicultura: autonomia?}

\section{Outras responsabilidades, interações e aprendizagens}

Assumir a titularidade de um contrato de integração com uma agroindústria implica novas responsabilidades e contatos, independentemente dos motivos para assiná-lo e do grau de envolvimento das mulheres com as práticas agrícolas na dendeicultura. Como analisa Osório Hernández (2009), o fato de as mulheres entrevistadas possuírem contas bancárias e irem ao banco também as obriga a transitar em outros espaços públicos, socialmente atribuídos aos homens. Segundo a autora, isso permitiu igualmente às mulheres uma inserção em outras esferas da vida fora do ambiente doméstico, proporcionando-lhes reconhecimento social e contato com os agentes de mediação de diferentes instituições.

A participação em reuniões na empresa e a recepção da assistência técnica no estabelecimento são algumas das "obrigações", cujo exercício faz as mulheres circularem em outros universos. Todas as mulheres participaram de cursos promovidos pela empresa contratante sobre práticas culturais, gestão do cultivo etc. Nesses eventos, elas afirmam conhecer outras mulheres e apreciar trocar ideias. Para Sempre-Viva (31 anos, agricultora), foram ocasiões em que puderam saber o que estava acontecendo, exigir o prometido pela empresa e, principalmente, conversar com outros produtores sobre as dificuldades impostas pela produção do dendê e também por problemas no roçado. No retorno as suas localidades, os aprendizados são socializados com a família e amigos, o que contribui para o seu reposicionamento. Relata Alfazema (71 anos, aposentada): "escutava o que era e o que não era para fazer ao conversar com os técnicos da empresa sobre as dificuldades”. Nigela (66 anos, aposentada) afirmou: "os meus filhos trabalham como eu oriento, pois foi a forma que os técnicos ensinaram”.

As mulheres demonstraram ter aprendido novas técnicas produtivas. Segundo uma agricultora, "aprendeu na prática como trabalhar no dendê":

Aprendi a adubar, o itinerário técnico, o tempo de florescência, período de zelar e adubar, usar puerária. (Sempre-Viva, 31 anos, agricultora, casada)

Porque os cuidados que a gente não tinha e agora tem, as normas de segurança do trabalho, o adubo e o veneno. A gente vai aprendendo, foram tantas coisas novas. (Íris, 36 anos, agricultora, casada)

Porque eu aprendi muito sobre a segurança do trabalho, criação de peixes. Eu fui a quatro palestras, todas muito legais, e a gente aprende muito, por exemplo, como usar o veneno, tirar o cacho e organizar as 
ferramentas. E quando a gente paga diária tem por obrigação dizer como tem que ser feito. (Margarida, 47 anos, solteira, agricultora)

Esses depoimentos têm em comum o reconhecimento do acesso a novos conhecimentos. Antes eram apenas os homens que participavam de formações sobre técnicas produtivas nos eventos nas localidades e nos Sindicatos de Trabalhadores e Trabalhadoras Rurais (STTRs), além de dialogarem com os técnicos da extensão em visita ao estabelecimento por serem considerados o "chefe de família". Eles mantêm-se assim, mas condicionantes do contrato implicam redefinições, nem sempre tranquilas.

A participação das mulheres nas reuniões tanto amplia o contato com pessoas de mundos sociais diferentes como proporciona novas experiências e contribui para romper com o modelo hegemônico no qual as mulheres predominam nos cuidados com o grupo doméstico, enquanto os homens participam dos processos externos à família (NEVES; MOTTA-MAUÉS, 2013).

Segundo Zanini e Santos (2013), o reposicionamento das mulheres causa conflitos e, muitas vezes, vergonha e constrangimento devido ao contato reduzido nesses ambientes. Mesmo assim, as autoras concluem que a participação das mulheres na esfera pública é positiva. Isso também foi constatado entre as mulheres titulares dos contratos de produção nesta pesquisa.

Os resultados encontrados por Barbosa e Lerrer (2016) comparam-se aos depoimentos das mulheres com contratos de produção, pois se constata que o contrato, assim como o benefício do Bolsa Família, favorece a participação em outros espaços e o contato com outras pessoas.

\section{Influência do engajamento econômico na autonomia ou na subordinação}

Todas as mulheres que assinaram contrato têm acesso a recursos financeiros provenientes do crédito Pronaf Eco Dendê ${ }^{9}$ que se destinam ao financiamento do cultivo do dendê e foram depositados nas contas bancárias de 26 mulheres (86\%) e de procuradores, no caso de quatro mulheres (14\%).

As mulheres concordam que o financiamento foi condicionado ao contrato, mas isso não significa que os recursos ficaram à disposição delas, que são titulares, já que são os homens que predominantemente os monopolizam, tendendo a decidir sobre sua utilização. Nesse universo, apenas quatro mulheres (14\%) afirmaram possuir autonomia para decidir sobre os recursos financeiros. Outras $30 \%$ afirmaram que o casal decidiu,

\footnotetext{
${ }^{9}$ O Pronaf Eco é uma linha de crédito destinada a financiar especificamente projetos para a cultura do dendê ou seringueira. O investimento do crédito consiste em custear as despesas com a implantação e a manutenção da cultura até o quarto ano. Para a cultura do dendê, o prazo de pagamento é de 14 anos, incluindo até 6 (seis) anos de carência; para a seringueira, o prazo é de até 20 anos, com até 8 (oito) anos de carência. As taxas de juros são de 5,5\% a.a., conforme o crédito solicitado. O limite do crédito para a cultura do dendê é de $\mathrm{R} \$ 8.800,00$ (oito mil e oitocentos reais) por hectare e, para a seringueira, $\mathrm{R} \$ 16.500,00$ (dezesseis mil e quinhentos reais) por hectare (CANAL RURAL, 2015).
} 
enquanto para 17 mulheres (56\%), foram os homens que decidiram sobre o uso dos recursos. Nem a titularidade da terra nem o contrato foram suficientes para que as mulheres assumissem o controle dos recursos e a tomada de decisão. Mas, assim como demonstrado por Barbosa e Lerrer (2016) no que tange às mulheres beneficiadas com lotes da reforma agrária, o fato de ser a titular é determinante para que haja possibilidades de negociação das mulheres com os demais familiares.

Quando analisamos a autonomia para usar e administrar os recursos financeiros por grupos de decisão, notamos que no grupo com decisão própria apenas três mulheres (30\%) possuem liberdade para tal. Isso significa que ter um contrato no próprio nome por opção não garante autonomia a todas as mulheres desse grupo para gerir os recursos.

Nos casos em que a decisão para realizar o contrato foi de um homem da família, é ele que decide sobre o uso dos recursos financeiros, sem que nenhuma mulher questione.

No Rio Grande do Sul, Osório Hernández (2009) observou que as mulheres que buscavam obter o crédito não o fizeram somente para ter acesso a uma política pública de caráter econômico, mas, em algumas situações, para atender ao pedido de algum membro familiar que não conseguiria obter diretamente o crédito. Verificamos a semelhança que há nos casos do grupo de mulheres que apenas atendeu ao pedido de um homem da família para assinar um contrato para a produção de dendê, uma vez que, nesse grupo, elas não se envolveram em nenhuma decisão quanto aos gastos dos recursos.

Em relação ao grupo de mulheres em que a decisão pelo contrato foi tomada pela família, apenas quatro mulheres (40\%) afirmaram decidir conjuntamente sobre os gastos dos recursos. Portanto, a gestão dos recursos financeiros não foi compartilhada em $60 \%$ dos casos. Nesse grupo, uma das mulheres tornou-se responsável pela gestão dos recursos após o marido recusar-se a administrar o dendê por não se identificar com o trabalho e ter medo de inadimplência. A mulher, por sua vez, para não ficar em dívida com o banco, responsabilizou-se pelas diferentes atividades do cultivo com muita dedicação.

Embora a grande maioria das mulheres, em todos os grupos, não administre os recursos financeiros, houve casos em que o acesso ao crédito proporcionou melhores condições de negociar com seus maridos. Um exemplo:

A mulher pode dar opinião, pode dizer o que fazer agora e tenho como opinar sobre o projeto que está em meu nome, e dizer como o dinheiro será investido. A mulher junto com o marido vai incentivando um ao outro para melhorar a condição da família, trabalhando juntos e fazer as coisas funcionarem. Aprender a trabalhar com um projeto ajuda a 
mulher, a saber, a trabalhar com dinheiro, negociar, fazer as coisas com o marido, mas não esperar só por ele. (Sempre-Viva, 31 anos, agricultora, casada)

Independentemente do fato de administrarem ou não o dinheiro, as mulheres foram unânimes ao afirmar que o "dendê traz renda para a família” e que, de modo geral, essa renda é investida nos tratos necessários ao seu cultivo e na compra de alimentos. $O$ crédito também foi utilizado para apoiar as atividades produtivas e até para alimentação em momentos em que o roçado não estava sendo suficiente para o sustento da família.

No conjunto de mulheres, sete são beneficiárias do Bolsa Família, ${ }^{10}$ outras sete recebem aposentadoria e quatro comercializam urucum e farinha. Constatamos, em consonância com a literatura, que esses recursos ficam nas mãos das mulheres e contribuem para equilibrar os gastos necessários ao grupo doméstico (OSÓRIO HERNÁNDEZ, 2009; CINTRÃO; SILIPRANDI, 2011; BARBOSA, 2013; BARBOSA; LERRER, 2016). Particularmente, o Bolsa Família contribui para o processo de emancipação feminino, transcendendo o caráter monetário e, sobretudo, proporcionando maior visibilidade na sociedade e poder de decisão dentro e fora da família (REGO; PINZANI, 2013). Entretanto, 12 mulheres não possuem renda proveniente de atividades produtivas ou programas sociais.

O uso múltiplo dos recursos chama a atenção para a complexa rede de relações em que se apoia o trabalho familiar no mundo rural, diferente do universo urbano (PAULILO; BONI, 2009).

\section{A visão da própria experiência}

Na pesquisa de campo, notamos, de início, a reação de estranhamento e a timidez das mulheres quando lhes perguntamos sobre a titularidade do contrato de produção. $O$ trabalho de Paulilo (2003) sobre herança da terra e a exclusão das mulheres desse processo mostrou que "espaço público e vergonha andam juntos na educação feminina" (PAULILO, 2003, p. 15). Porém, essa vergonha não significa que elas não soubessem falar sobre suas escolhas (em $87 \%$ dos casos); mas, por uma questão de hierarquia familiar, acreditam que deve caber ao homem - visto como o chefe de família - fazer contato com atores externos. Segundo Paulilo (2003, p. 15), "as entrevistadas falam do 'medo de falar

\footnotetext{
${ }^{10}$ Trata-se de um programa de transferência de renda que contempla famílias com rendimento mensal per capita entre R\$ 60,00 e R\$ 120,00 , ou seja, famílias que se encontram em situações de vulnerabilidade social. Os valores pagos variam de acordo com o rendimento mensal per capita da família e de acordo com o número de crianças e adolescentes que frequentam a escola. Entre outros objetivos, o programa visa reduzir a pobreza e a subnutrição, de acordo com o Ministério do Desenvolvimento Social. Segundo Rego e Pinzani (2013), o cadastro do programa de transferência estatal de renda está principalmente em nome das mulheres pobres. Defende-se nesta pesquisa a hipótese de que a renda monetária é capaz de produzir e de desenvolver espaços pessoais de liberdade dos sujeitos, oferecendo-lhes, como resultado, mais possibilidades de autonomia para a vida de modo geral.
} 
bobagem', pois sabem muito bem como o ridículo é uma arma poderosa”. Entretanto, pouco a pouco, barreiras foram vencidas, e elas discorreram sobre a importância de ter um contrato no próprio nome:

É algo novo que muda a cabeça da gente, a gente aprende a negociar e ver as dificuldades de um trabalho que as mulheres não tinham contato, a gente vai aprendendo a se virar com essas coisas. (Dália, 30 anos, agricultora, casada)

Melhorou muito depois que peguei o projeto, é a primeira vez que faço um projeto no meu nome. Estou aprendendo como funciona, mesmo quando meu marido não está por perto, eu sei o que tem que pedir para os trabalhadores fazerem com o dendê. (Amarílis, 23 anos, agricultora, casada)

Já é o segundo projeto em meu nome, daí eu já sei direito como trabalhar com os documentos no banco. Além disso, a gente trabalha, e ter direito sobre o nosso trabalho é bom pra todos. (Aurora, 50 anos, agricultora, casada)

O contrato é algo novo, diferente, e eu que sou a responsável por ele, faço de tudo pra ele dar certo e melhorar a vida da família. (Papoula, 29 anos, agricultora, solteira)

Os depoimentos mostram que as mulheres têm consciência da importância de ter contratos nos seus nomes como uma forma de "torná-las visíveis e mais valorizadas" (PAULILO, 2003, p. 2). Isso não significa que seu trabalho no roçado de mandioca não tivesse importância, mas que a partir da assinatura do contrato, elas estão reorganizando sua autoimagem, valorizando seu trabalho, adquirindo novos conhecimentos e, principalmente, reconhecendo as mudanças que esse processo proporciona. Trata-se, a nosso ver, do prenúncio de construção de autonomia.

Para Romano e Antunes (2002), a autonomia consiste em um objetivo a ser alcançado em processos de empoderamento e tem suas bases nas relações de poder. Assim, a autonomia das mulheres concretiza-se na medida em que há mudanças perceptíveis nas relações de poder entre os sexos e, por conseguinte, nas estruturas que reproduzem a hierarquia masculina à qual as mulheres estão subordinadas. Segundo os depoimentos mostrados anteriormente, tem havido mudanças nas relações entre as mulheres e seus familiares, técnicos e vizinhança. Muito embora elas não questionem a subordinação existente nas relações familiares, elas apresentam liberdade para narrar suas histórias diante de terceiros, dando vazão às experiências, expectativas e sentimentos vivenciados com tal situação.

Nos estudos que analisaram dinâmicas sociais em que mulheres participavam de programas de crédito e assinavam contratos em seus nomes, a autonomia foi 
questionada nos diferentes processos de decisão, dentro e fora da família (BONI, 2005; MARTÍNEZ DAJUI, 2006; FERNANDES, 2008; CÂNDIDO, 2009; OSÓRIO HERNÁNDEZ, 2009). Nesses estudos, há consenso quanto às mudanças materiais e simbólicas proporcionadas às mulheres que lhes possibilitaram novos desafios e oportunidades de socialização. Logo, apesar de haver ganhos e conquistas, é necessário avaliar outros aspectos, além da aquisição econômica, geralmente interpretada como autonomia.

No caso das mulheres com contratos de produção, reconhecemos a importância da experiência e os seus depoimentos manifestam várias dimensões da autonomia:

Eu resolvo tudo, aprendi a me virar. O meu marido não se envolve com coisas grandes, se eu não fizesse o contrato, eles nunca iriam sair do serviço da mandioca. (Dália, 30 anos, casada, agricultora)

O fato de o contrato estar em meu nome está fazendo com que projeto vá para frente, se fosse no nome do meu marido talvez nem desse certo. (Flor de Lótus, 30 anos, agricultora, casada)

Os depoimentos anteriores anunciam que pequenas mudanças ocorreram nas relações familiares e com diferentes atores sociais. Essas mudanças correspondem ao que a literatura aponta como processos de autonomia.

Segundo as reflexões de Barbosa e Lerrer (2016), a autonomia é processual e relacional porque depende dos caminhos e das reconfigurações construídas entre as partes envolvidas. Neste estudo, notamos que parte considerável das mulheres que assinou contrato para a produção de dendê tem experimentado mudanças nos papéis socialmente assumidos, quer seja no estabelecimento familiar, quer seja em outros espaços, e, em variadas ações, tem demonstrado certa autonomia.

\section{Considerações finais}

Nosso objetivo neste artigo foi analisar a participação das mulheres em iniciativas econômicas, examinando se tais experiências têm repercutido na conquista de sua autonomia. Tomamos como evidência empírica mulheres titulares de contratos de integração para a produção de dendê no município de São Domingos do Capim, Pará, maior produtor de dendê do Brasil.

Em comum, as mulheres visam melhorias na qualidade de vida de suas famílias por meio da assinatura do contrato, que garante o financiamento do cultivo de dendê. Logo, a assinatura de um contrato de integração por uma mulher representa uma solução para que a família tenha acesso ao crédito.

Concluímos que há uma relação direta entre a decisão da própria mulher em assinar o contrato e o envolvimento nas diferentes atividades ligadas ao cultivo do dendê, em cuja gestão as mulheres obtiveram maior autonomia. 
A conquista da autonomia ficou mais evidente em três mulheres cujos contratos de produção foram feitos por decisão própria. Para elas, a construção da autonomia foi maior em relação à independência para tomar decisões no estabelecimento e na participação em eventos das esferas públicas (ir ao banco, envolver-se em reuniões e capacitações, dialogar com representantes de instituições públicas e privadas e com os técnicos da empresa dendeicultora) em conjunto coma obtenção de recursos financeiros.

É interessante destacar que o contrato em nome das mulheres foi decisivo para que tivessem acesso a diferentes informações e assumissem novos papéis. Em qualquer uma dessas situações, as mulheres apropriaram-se de conhecimento e atuaram como socializadoras em suas famílias e na comunidade. Depreendemos que a posição delas foi reorientada, visto que houve uma ruptura na condição dos homens como detentores de informações, conhecimento e socialização com reflexos na construção da sua autonomia.

Podemos inferir que a assinatura de um contrato de produção representou para as mulheres uma estratégia de conquista da autonomia, embora essa autonomia nem sempre seja exercida da mesma forma ou mesmo questionada. Em comparação com sua situação anterior, por exemplo, elas reconhecem que aprenderam e praticam novas atividades, novas relações sociais, e, em alguns casos, têm mais consciência de sua participação, contribuição e controle das atividades produtivas dentro do grupo familiar.

\section{Referências bibliográficas}

ABRAPALMA - Associação Brasileira de Produtores de Óleo de Palma. Sobre a Abrapalma. Página inicial, 2015. Disponível em: http://www.abrapalma.org/pt/sobre-a-abrapalma/. Acesso em: 20 jan. 2020.

AQUINO, S. L. de. Estratégias empresariais e efeitos locais: a integração de pequenos agricultores à indústria fabricante de papel e celulose. Revista IDeAS, v. 7, n. 3 (especial), p. 158-197, 2013. Disponível em: https://revistaideas.ufrrj.br/ojs/index.php/ideas/article/view/121. Acesso em: 15 dez. 2019.

ARNDT, C.; BENFICA, R.; THURLOW, J. Gender implications of biofuels expansion in Africa: The case of Mozambique. World Development, v. 39, n. 9, p. 1649-1662, 2011.

BANCO DA AMAZÔNIA. Coordenadoria de Agricultura Familiar. Sistema de Relatórios. Belém, 2015.

BARBOSA, M. L. D. A.; LERRER, D. F. O gênero da posse da terra: um estudo sobre o poder de negociação de mulheres titulares de lotes via reforma agrária. Revista Brasileira de Sociologia, v. 4, n. 8, p. 243-274, 
2016. Disponível em: http://www.sbsociologia.com.br/rbsociologia/index.php/rbs/article/view/244. Acesso em: 5 dez. 2019.

BARBOSA, V. O. Participação feminina e resistência camponesa no Maranhão do século XX. In: NEVES, D. P; MEDEIROS, L. S. de (Orgs.). Mulheres camponesas: trabalho produtivo e engajamentos políticos. Niterói: Alternativa, 2013. p. 283-302.

BONI, V. Produtivo ou reprodutivo: o trabalho das mulheres nas agroindústrias familiares - um estudo na região Oeste de Santa Catarina. 2005. 99 f. Dissertação (Mestrado em Sociologia Política) - Centro de Filosofia e Ciências Humanas, Universidade Federal de Santa Catarina, Florianópolis, 2005. Disponível em: https://repositorio.ufsc.br/handle/123456789/102731. Acesso em: 21 out. 2019.

BRANDÃO, F.; SCHONEVELD, G.; PACHECO, P. Integração da agricultura familiar à cadeia da palma de óleo na Amazônia brasileira: análise e recomendações. Infobrief, n. 207. Bogor: Cifor, 2018.

BRUMER, A. Gênero e agricultura: a situação da mulher na agricultura do Rio Grande do Sul. Estudos Feministas, v. 12, n. 1, p. 205-227, 2004. Disponível em: https://periodicos.ufsc.br/index.php/ref/article/view/s0104-026X2004000100011/8695. Acesso em: 5 set. 2019.

BRUSCHINI, M. C. A. Trabalho e gênero no Brasil nos últimos dez anos. Cadernos de Pesquisa, v. 37, n. 132, p. 537-572, 2007. Disponível http://publicacoes.fcc.org.br/ojs/index.php/cp/article/view/340. Acesso em: 20 ago. 2019.

CANAL RURAL. Pronaf Eco Dendê/Seringueira - Investimento. 2015.

CÂNDIDO, M. H. Dinâmicas sociais de gênero a partir da concessão do crédito pecuário a mulheres rurais do Posto Administrativo de Changalane em Maputo-Moçambique. 2009. 202 f. Dissertação (Mestrado em Desenvolvimento Rural) - Faculdade de Ciências Econômicas, Universidade Federal do Rio Grande do Sul, Porto Alegre, 2009. Disponível em: https://www.lume.ufrgs.br/handle/10183/18839/. Acesso em: 30 jul. 2019.

CINTRÃO, R. P.; SILIPRANDI, E. O progresso das mulheres rurais. In: BARSTED, L. L.; PITANGUY, J. (Orgs.). O progresso das mulheres no Brasil 2003-2010. Rio de Janeiro: Cepia; Brasília: ONU Mulheres, 2011. p. 186-230.

FERNANDES, S. A. Gênero e políticas de crédito: o Pronaf-Mulher em Santa Catarina. 2008. $138 \mathrm{f}$. Dissertação (Mestrado em Sociologia Política) - Departamento de Sociologia e Ciência Política, Universidade Federal de Santa Catarina, Florianópolis, 2008. Disponível em: https://repositorio.ufsc.br/xmlui/handle/123456789/91928. Acesso em: 15 dez. 2019.

FERNANDES, T.; MOTA, D. M. "É sempre bom ter o nosso dinheirinho”: sobre a autonomia da mulher no extrativismo da mangaba no Pará. Revista de Economia e Sociologia Rural, Piracicaba, v. 52, n. 1, p. 9 24, 2014. Disponível em: https://doi.org/10.1590/S0103-20032014000100001. Acesso em: 22 nov. 2019.

FERRANTE, V. L. S. B.; DUVAL, H. C.; BergamasCO, S. M. P. P.; BOLFE, A. P. F. Na trajetória dos assentamentos rurais: mulheres, organização e diversificação. In: NEVES, D. P.; MEDEIROS, L. S. de (Orgs.). Mulheres camponesas: trabalho produtivo e engajamentos políticos. Niterói: Alternativa, 2013. p. $195-216$.

GOMES, L. S.; MAGALHÃES, S. B. Agricultores integrados do dendê e questões relativas ao sistema de produção no PA, Terra Nova. EcoDebate, 30 mai. 2016. Disponível em: https://www.ecodebate.com.br/2016/05/30/agricultores-integrados-do-dende-e-questoesrelativas-ao-sistema-de-producao-no-pa-terra-nova-por-lucinaldo-soares-gomes-e-sonia-barbosamagalhaes/. Acesso em: 31 jan. 2020. 
HIRATA, H.; KERGOAT, D. Novas configurações da divisão sexual do trabalho. Cadernos de Pesquisa, São Paulo, v. 37, n. 132, p. 595-609, set./dez. 2007. Disponível em: https://www.scielo.br/pdf/cp/v37n132/a0537132.pdf. Acesso em: 19 nov. 2019.

LI, T. M. The gendered dynamics of Indonesia's oil palm labour regime. Working Paper Series n. 225. Singapore: Asia Research Institute, 2014.

MARIN, J. O. B.; REDIN, E.; COSTA, F. F. Juventude rural e trabalho no cultivo do tabaco. Revista Latinoamericana de Estudios del Trabajo, v. 19, n. 31, p. 159-194, 2014.

MARTÍNEZ DAJUI, E. A construção da cidadania através da identidade socioprofissional das mulheres rurais que participam em programas de microfinanciamento. 2006. 280 f. Tese (Doutorado em Sociologia) Instituto de Filosofia e Ciências Humanas, Universidade Federal do Rio Grande do Sul, Porto Alegre, 2006. Disponível em: https://lume.ufrgs.br/handle/10183/7907. Acesso em: 30 out. 2019.

MARTINEZ, R. V. Capital social, participação e cidadania no meio rural: uma perspectiva de gênero. 2010. 290 f. Tese (Doutorado em Sociologia) - Programa de Pós-graduação em Sociologia, Instituto de Filosofia e Ciências Humanas, Universidade Federal do Rio Grande do Sul, Porto Alegre, 2010. Disponível em: https://lume.ufrgs.br/handle/10183/25405. Acesso em: 30 out. 2019.

MELO, H. P.; DI SABBATO, A. Um olhar de gênero nos assentamentos da reforma agrária. In: LOPES, A. L.; ZARZAR, A. B. (Orgs.). Mulheres na reforma agrária: a experiência recente no Brasil. Brasília: NEAD, 2008. p. 153-184.

MONTEIRO, K. F. G. Análise de indicadores de sustentabilidade socioambiental em diferentes sistemas produtivos com palma de óleo no estado do Pará. 2013. 205 f. Tese (Doutorado em Ciências Agrárias) Embrapa Amazônia Oriental, Universidade Federal Rural da Amazônia, Belém, 2013.

NAHUM, J. S.; BASTOS, C. S. Dendeicultura e descampesinização na Amazônia Paraense. CampoTerritório: Revista de Geografia Agrária, Uberlândia, v. 9, n. 17, p. 469-485, abr. 2014. Disponível em: http://www.seer.ufu.br/index.php/campoterritorio/article/view/23628. Acesso em: 13 set. 2019.

NAHUM, J. S.; MURRAY, J. D. Impactos socioespaciais da dendeicultura no Brasil e na Colômbia. In: CONGRESSO BRASILEIRO DE GEÓGRAFOS, 9., Vitória, 2014. Anais... São Paulo: AGB, 2014. p. 1-11.

NEVES, D. P. Mulheres e mercado de trabalho: aflições e conquistas. Coleção Mulheres em Santarém: Alternativas de vida, v. 1. Niterói: Alternativa, 2014.

NEVES, D. P.; MOTTA-MAUÉS, M. A. Apresentação. In: NEVES, D. P.; MEDEIROS, L. S. de (Orgs.). Mulheres camponesas: trabalho produtivo e engajamentos políticos. Niterói: Alternativa, 2013. p. 17-40.

OSÓRIO HERNÁNDEZ, C. Política de crédito rural com perspectiva de gênero: um meio de "empoderamento" para as mulheres rurais? 2009. 248 f. Tese (Doutorado em Desenvolvimento Rural) - Faculdade de Ciências Econômicas, Universidade Federal do Rio Grande do Sul, Porto Alegre, 2009. Disponível em: https://lume.ufrgs.br/handle/10183/16405. Acesso em: 8 ago. 2019.

PAULILO, M. I. S.; BONI, V. Agricultura e maricultura familiares: um recorte de gênero. In: JORNADAS DEL CENTRO INTERDISCIPLINARIO DE INVESTIGACIONES EN GÉNERO, 1., La plata, 2009, La Plata. Anais... La Plata: Universidad Nacional de La Plata, 2009. Disponível em: http://www.memoria.fahce.unlp.edu.ar/trab_eventos/ev.3891/ev.3891.pdf. Acesso em: 4 nov. 2019.

PAULILO, M. I. S. Movimento de mulheres agricultoras: terra e matrimônio. In: PAULILO, M. I. S.; SCHMIDT, W. (Orgs.). Agricultura e espaço rural em Santa Catarina. Florianópolis: UFSC, 2003. p. 183210.

PAULILO, M. I. S. O peso do trabalho leve. Ciência Hoje, Rio de Janeiro, v. 5, n. 28, p. 64-70, 1987.

PAULILO, M. I. S. Produtor e agroindústria: consensos e dissensos. Florianópolis: UFSC, 1990.

REGO, W. D. L.; PINZANI, A. Liberdade, dinheiro e autonomia: o caso da Bolsa Família. Política \& Trabalho, João Pessoa, n. 38, p. 21-42, 2013. Disponível em: 
https://periodicos.ufpb.br/ojs/index.php/politicaetrabalho/article/view/15029. Acesso em: 11 out. 2019.

REIGADA, A. Um olhar feminista sobre o trabalho nas cadeias agrícolas globais. Contemporânea, São Carlos, v. $4, \quad$ n. $\quad 1, \quad$ p. 19-41, 2014. Disponível em: http://www.contemporanea.ufscar.br/index.php/contemporanea/article/view/191. Acesso em: 23 set. 2019.

REUTERS. ADM tem aval para venda de negócios de plantio e cultivo de palma no Brasil. Portal R7, São Paulo, 6. jan. 2020. Correio Braziliense, Brasília, 4 jun. 2014. Tecnologia. Disponível em: https://noticias.r7.com/economia/adm-tem-aval-para-venda-de-negocios-de-plantio-e-cultivo-depalma-no-brasil-06012020. Acesso em: 5 mar. 2020.

RIBEIRO, J. E. L. S. R.; HOPKINS, M. J. G.; VICENTINI, A.; SOTHERS, C. Flora da Reserva Ducke: guia de identificação das plantas vasculares de uma floresta de terra-firme na Amazônia Central. Manaus: Inpa, 1999.

ROMANO, J. O.; ANTUNES, M. (Orgs.). Empoderamento e direitos no combate à pobreza. Rio de Janeiro: ActionAid Brasil, 2002.

SAMPAIO, I. C. A agricultura familiar e a agroindústria do dendê no município de Tomé-Açu (PA): efeitos da agricultura por contrato na produção e no trabalho familiar. 2014. 205 f. Dissertação (Mestrado em Sociologia e Antropologia) - Instituto de Filosofia e Ciências Humanas, Universidade Federal do Pará, Belém, 2014.

SCHEFLER, M. L. N. Gênero, autonomia econômica e empoderamento. O real e o aparente: sistematização de processos de investigação-ação e/ou de intervenção social. Feminismos, Salvador, v. 1, n. $3, \quad$ p. $1-20, \quad 2013 . \quad$ Disponível https://portalseer.ufba.br/index.php/feminismos/article/view/29988. Acesso em: 5 set. 2019.

SILIPRANDI, E. Rompendo a inércia institucional: as mulheres rurais e a Política Nacional de Agroecologia e Produção Orgânica. In: SAMBUICHI, R. H. R. et al. (Orgs.). A política nacional de agroecologia e produção orgânica no Brasil: uma trajetória de luta pelo desenvolvimento rural sustentável. Brasília: Ipea, 2017. p. 277-294.

SOARES, V. Mulher, autonomia e trabalho. In: FUNDAÇÃO ALEXANDRE DE GUSMÃO. Autonomia econômica e empoderamento da mulher: textos acadêmicos. Brasília: FAG, 2011. p. 281-301.

SOUSA, C. F. M. Projetos de desenvolvimento para a Amazônia: a expansão da dendeicultura. In: SEMINÁRIO INTERNACIONAL AMÉRICA LATINA: POLÍTICAS E CONFLITOS CONTEMPORÂNEOS, 2., Belém, 2015. Anais... Belém: NAEA/UFPA, 2015. p. 15-29.

SOUZA, J. A. A. Nas ondas da pororoca: repercussões socioespaciais da atividade turística no município de São Domingos do Capim (Pará). 2006. 134 f. Dissertação (Mestrado em Geografia) - Centro de Filosofia e Ciências Humanas, Universidade Federal do Pará, Belém, 2006. Disponível em: http://repositorio.ufpa.br/jspui/handle/2011/1875. Acesso em: 4 dez. 2019.

TERSSAC, G. de. Autonomie. In: BEVORT, A. et al. (Orgs.). Dictionnaire du travail. Paris: Presses Universitaires de France, 2012. p. 49-53.

VALE, S. R. G. A. Avaliação do perfil das quebradeiras de coco babaçu e de suas condições de trabalho no município de Itapecuru-Mirim/MA. 2015. 112 f. Dissertação (Mestrado Interinstitucional em Saúde Pública e Meio Ambiente) - Escola Nacional de Saúde Pública Sérgio Arouca, Fundação Oswaldo Cruz, Rio de Janeiro, 2015. Disponível em: https://www.arca.fiocruz.br/handle/icict/14054. Acesso em: 28 ago. 2019.

VIEIRA, A. C. C. A “integração" camponesa ao monocultivo de dendê: subordinação e transformação do campesinato amazônico. 2015. 205 f. Dissertação (Mestrado em Agricultura Familiar e 
Desenvolvimento Sustentável) - Núcleo de Ciências Agrárias e Desenvolvimento Rural, Universidade Federal do Pará, Belém, 2015.

WEDIG, J. C. Agricultoras e agricultores à mesa: um estudo sobre campesinato e gênero a partir da antropologia da alimentação. 2009. 166 f. Dissertação (Mestrado em Desenvolvimento Rural) Faculdade de Ciências Econômicas, Universidade Federal do Rio Grande do Sul, Porto Alegre, 2009. Disponível em: https://lume.ufrgs.br/handle/10183/22660. Acesso em: 13 out. 2019.

ZANINI, M. C. C.; SANTOS, M. O. Colônias italianas no Sul do Brasil: estigma e identidade. In: NEVES, D. P.; MEDEIROS, L. S. de (Orgs.). Mulheres camponesas: trabalho produtivo e engajamentos políticos. Niterói: Alternativa, 2013. p. 89-106.

ZORZI, A. Uma análise crítica da noção de empoderamento com base no acesso das agricultoras ao Pronaf Mulher em Ijui - RS. 2009. 167 f. Dissertação (Mestrado em Sociologia) - Instituto de Filosofia e Ciências Humanas, Universidade Federal do Rio Grande do Sul, Porto Alegre, 2008. Disponível em: https://lume.ufrgs.br/handle/10183/15005. Acesso em: 2 set. 2019.

\section{Como citar}

NASCIMENTO, Diocélia; MOTA, Dalva Maria da. Mulheres na dendeicultura paraense: possibilidade de autonomia. Estudos Sociedade e Agricultura, Rio de Janeiro, v. 28, n. 3, p. 721-743, out. 2020. DOI: https://doi.org/10.36920/esa-v28n3-10. 